\title{
STUDY AND ANALYSIS OF THE STRUCTURE OF THE WORKING TIME OF COMBINE HARVESTER FOR HARVESTING OF WHEAT
}

\author{
Krasimir Trendafilov, Dragomir Dragoev \\ Faculty of Technics and Technologies, Trakia University, Bulgaria \\ 38 Graf Ignatiev str., 8600 Yambol, Bulgaria \\ e-mail: trendafilov@outlook.com,drago_dr13@abv.bg
}

\begin{abstract}
The harvesting is one of the most difficult and responsible operations in the crops growing. It should be done in the short term, in order to prevent losses of production. This requires efficient use of the operating time of the combine harvesters. A study of the working time of a combine harvester was carried out throughout the whole period of wheat harvesting. Unloading of the hopper is carried out when the combine harvester is stationary. It was found that the time to prepare and finish work was $24.754 \%$ of the total working time. It includes time for maintenance of the combine harvester, the time for coupling and uncoupling of the combine header, the time for transport of the combine harvester to and from the field, and the time for moving inside the field. It was found that the time of harvesting is $53,158 \%$ of the working time. Non-productive time in the field represents $22,088 \%$ of the total working time. It includes the time for the movement of combine harvester to the place of unloading and vice versa, the time for waiting before unloading, the unloading time, the time for making turns, the time for updating of the technological settings, the time for searching and troubleshooting. For unloading of grain tank is lost $14.842 \%$ of working time. On the basis of the study, an algorithm for the operation of a combine harvester was made when unloading in stationary.
\end{abstract}

Key words: combine harvester, harvest, working time, algorithm.

\section{INTRODUCTION}

One of the most labor-intensive processes in agriculture is the harvesting of cereals. It is related to a rather complex organization of work of combine harvesters, transport units, organization of grain reception points. Furthermore, harvesting must be carried out in a short time to prevent grain losses due to the extended harvesting period [2].

Many farmers, in order to cope with the short harvest time, increase the number of combine harvesters or buy combines with high theoretical performance, but this does not automatically lead to greater actual performance. The organization at harvest is also essential. A proper work organization aims to increase the productive time at the expense of non-productive time. The unloading of the hopper of the grain harvester can be done in motion and in a stop position (Figure 1). The unloading of the combine hopper when combine is stopped leads to an increase in non-productive time, and hence a reduction in combine performance. This way of unloading is widely used in Bulgaria. It was found that in $91 \%$ of the farms unloading is carried out in a stopped position and in only $9 \%$ of them unloading is carried out in motion [4].

Unloading of the hopper can be carried out in the field or outside the field depending on the operating conditions and the means of transport used. When there is a great distance between field and the place of unloading may be used grain trucks for the transportation of grain. In this case, the unloading is carried out outside the field for a number of reasons, such as reducing soil compaction, etc. 


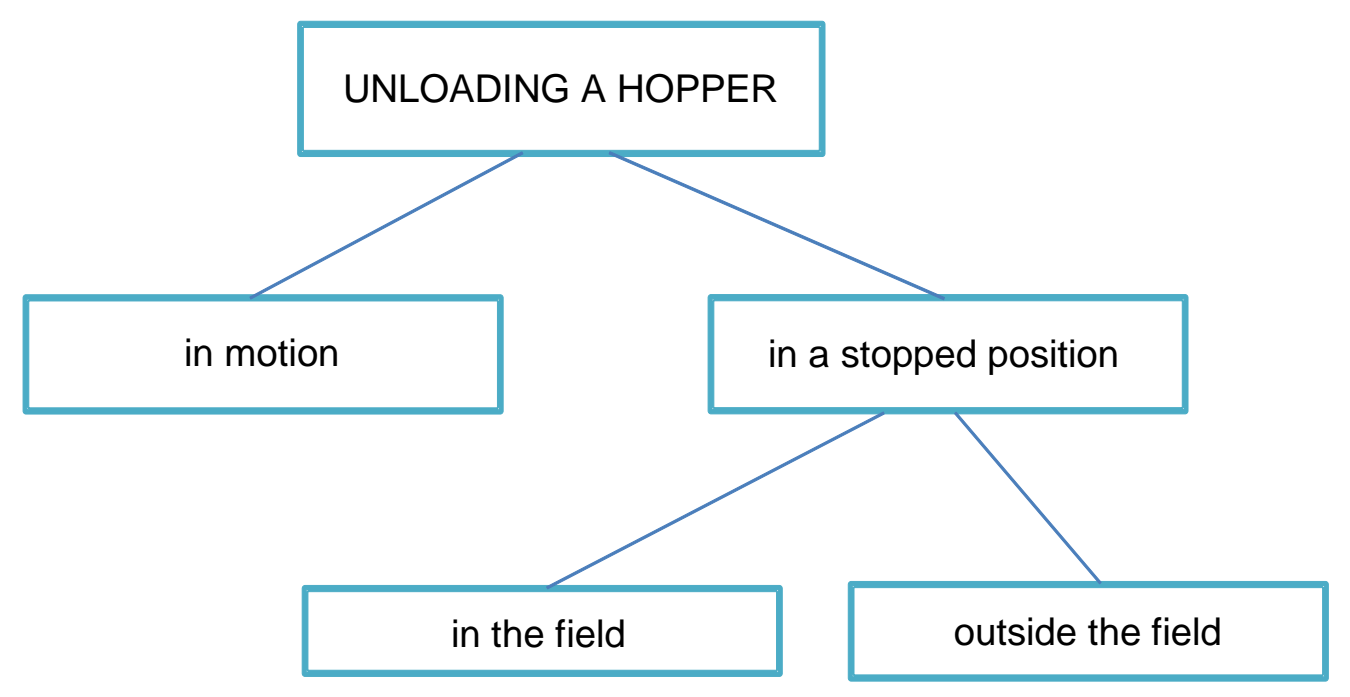

Figure 1. Ways to unload the grain hopper of the combine

According to some authors, when unloading the grain hopper in stopped position in the field, the combine harvesting performance is reduced by $14 \%$ and in unloading at the end of the field by $23 \%$. The processing time per unit area is increased by $15 \%$ and $30 \%$ respectively [1]. When unloaded in stopped position, an incomplete hopper is usually unloaded. Approximately $1 \mathrm{~m}^{3}$ of the hopper is not used and the number of unloading stops increases by about $11 \%$, resulting in lower productivity [3]. Only $37 \%$ of the unloading time is used for work of unloading auger. The rest of the time is lost for moving the combine or the truck and positioning for unloading [2]. Because an average of $73 \%$ of the flow rate of the unloading auger is used, the unloading time is $43 \%$ greater than the theoretical [5]. The work of individual authors provides detailed information on the duration of separate operations in harvesting and mainly for unloading the grain hopper. No information is available on all processes such as preparation of the harvester, its transportation and service during the harvest.

The purpose of the study is to examine and analyze the full working time of the combine harvester for the entire duration of the harvesting of wheat.

\section{MATERIAL AND METHOD}

The study was carried out during the harvest campaign in 2017 between 21.06 and 15.07 and covered a period of 25 working days. The total area occupied by wheat is 2160 ha. It is in the lands of the villages of Dryanovo, Drama, General Inzovo and Krumovo in Yambol province. The work of the CLAAS LEXION 570 grain harvester, working in a group with three grain combines ( 1 combine CLAAS LEXION 600, and 2 combines CLAAS LEXION 470) was observed. The combine harvester has a grain hopper volume of $10500 \mathrm{I}$, unloading auger flow rate of $100 \mathrm{l} / \mathrm{s}$, working width of $7.5 \mathrm{~m}$. The harvested crop is wheat variety Enola. The average yield was $5700 \mathrm{~kg} / \mathrm{ha}$, and the average humidity measured by the on-board moisture meter of the combine harvester $-12.1 \%$. Unloading of hopper is carried out in a stopped position of combine. By measuring with a stopwatch is determined duration of: 


\section{ARTTIE $Y$}

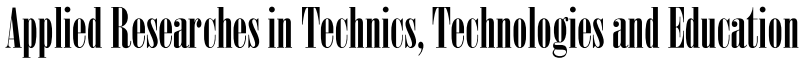

Journal of the Faculty of Technics and Technologies, Trakia University https://sites.google.com/a/trakia-uni.bg/artte/

Time for prepare and finish work:

- time for maintenance;

- time for coupling and uncoupling the header;

- time for transport the combine harvester to and from the field;

- time for moving the combine harvester in the field.

Productive time:

- time for filling the hopper.

Non-productive time in the field:

- time for the movement to combine harvester to the place of unloading and vice versa;

- time for stay before unloading;

- time for unload hopper;

- time for making turns;

- time for update the technology settings

- time for search and troubleshoot.

Total working time is determined by summing the times for the individual operations and the percentage of each operation of the total working time is determined. On the basis of the data obtained about the operations performed, an algorithm for work of combine harvester was designed.

\section{RESULTS AND DISCUSSION}

The results of the experimental study are shown in Table 1.

\subsection{Time for prepare and finish work}

The maintenance of the combine harvester is carried out at the beginning of the working day. It includes cleaning of dust and accumulated plant debris, refueling, lubricating, daily inspection of engine, header, thresher, separator and cleaner, as well as the condition of the screw connections. The study found that the maintenance time was 1642 min or $10.914 \%$ of the total working time. This time increases due to poor theoretical and practical training of the service staff, not knowing the machine, little practical experience, etc.

When the combine harvester moves from one field to another, coupling and uncoupling the header is performed. The time to perform this operation is 365 minutes or $2.426 \%$ of the total working time. This time can be reduced by improving the qualifications of the staff and reducing the number of combine harvesters working in the group. In this case, a group of four combine harvesters is used. After harvesting of one field, the whole group moves to the next field. This requires the header to be uncoupled and coupled each time when the combine is moved to a new field. In the case of a small number of combines in the group, the number of uncoupling and coupling of the header is reduced as the combine will work longer in one field.

Transport of combine harvester to and from the field is carried out after preparing the combine harvester to work made on the farm, after harvest the field, on completion of the working day and for return to the farm. The total transport time is $1530 \mathrm{~min}$ or $10.17 \%$ of the total working time. It may be reduced if after the end of the working day the combine harvesters are left in the field.

The time for moving of the combine harvester in the field include time for movement of the combine at idle to and from the working position in the field for various reasons. For the entire harvest period this time is $187 \mathrm{~min}$ i.e. $1.243 \%$ of total working time. 
Table 1. Result of experimental study

\begin{tabular}{|l|c|c|}
\hline \multicolumn{2}{|c|}{ Structure of working time } & \multicolumn{2}{|c|}{ Value } \\
\cline { 2 - 3 } & in minutes & in \% \\
\hline Time for prepare and finish work & & \\
\hline - time for maintenance & 1642 & 10.914 \\
\hline - time for coupling and uncoupling the header & 365 & 2.426 \\
\hline $\begin{array}{l}\text { - time for transport the combine harvester to and from } \\
\text { the field }\end{array}$ & 1530 & 10.170 \\
\hline - time for moving the combine harvester in the field & 187 & 1.243 \\
\hline$\quad$ Total & $\mathbf{3 7 2 4}$ & $\mathbf{2 4 . 7 5 4}$ \\
\hline Productive time & & \\
\hline - time for filling the hopper & 7997 & 53.158 \\
\hline Total & $\mathbf{7 9 9 7}$ & $\mathbf{5 3 . 1 5 8}$ \\
\hline Non-productive time in the field & & \\
\hline - time for the movement to combine harvester to the & 529 & 3.516 \\
\hline place of unloading and vice versa & & \\
\hline - time for stay before unloading & 806 & 5.357 \\
\hline - time for unload hopper & 898 & 5.969 \\
\hline - time for making turns & 390 & 2.592 \\
\hline - time for update the technology settings & 50 & 0.332 \\
\hline - time for search and troubleshoot & 650 & 4.320 \\
\hline Total & $\mathbf{3 3 2 3}$ & $\mathbf{2 2 . 0 8 8}$ \\
\hline Total working time & $\mathbf{1 5 0 4 4}$ & $\mathbf{1 0 0}$ \\
\hline
\end{tabular}

The total time for prepare and finish work is 3724 minutes or $24.754 \%$ of the total working time. It is seen that a significant part of the time is used for preparatory operations. Good organization and the high qualification of the staff may reduce this time to a minimum.

\subsection{Productive time}

The time for the real work of the combine is determined by the time to fill the grain hopper. From the table is seen that the combine harvester work 7997 min, i.e. $53.158 \%$ of the total working time. The relative share of productive time can be increased by decreasing the time for prepare and finish work as well as the other non-productive time in the field.

\subsection{Non-productive time in the field}

After filling the grain hopper, the grain harvester leaves the place on which it operates, moves to the transport unit and after unloading the hopper, returns to the working place in the field. This way of unloading is necessary because the fields are far away from the point of acceptance the grain and the transport is done by trucks that cannot move in the field or they too much compact the soil. The time for moving the combine to the unloading point and vice versa is $529 \mathrm{~min}$ or $3.516 \%$ of the total working time. It can be reduced by placing the vehicles in such a way as to reduce the distance traveled by the combine harvester to them. The time for stay of the combine harvester before unloading includes the waiting time for the arrival of the vehicle from the point of acceptance the grain. It can be seen that this time is 806 min or $5.357 \%$ of the total working time. The downtime can be reduced by better organization at the point of accepting, quick unloading and returning to the field or by increasing the number of transport vehicles.

IRTIIE Vol. 7, No. 4, 2019 ISSN 1314-8788 (print), ISSN 1314-8796 (online), doi: 10.15547/artte.2019.04.001 


\section{ARTTE $Y$}

Ipplied Resseirl'hes in Teednicis, Technologies and Eductation

Journal of the Faculty of Technics and Technologies, Trakia University https://sites.google.com/a/trakia-uni.bg/artte/

The time for unload the grain hopper of the combine is the time from switching on the unloading auger to shutting down the auger. Unloading is performed for 898 min or $5.969 \%$ of the total time.

The combine makes turns at the end on the field. These are non-working moves with total duration of 390 minutes or $2.592 \%$ of the total working time. The proportion of this time can be reduced by choosing the correct way of moving in the field and performing a turn.

Changing of the technology settings of combine takes 50 minutes or $0.332 \%$ of the total time. This time can be reduced by improving the qualifications of the staff and performing settings in movement wherever possible.

Time for search and troubleshoot include the time that the combine harvester passes from a workable to a malfunctioning state, detecting a malfunction, and removing it. The table shows that 650 minutes or $4.320 \%$ of the total working time is spent on these operations. It can be reduced by improving the qualifications of the staff and using modern diagnostic tools.

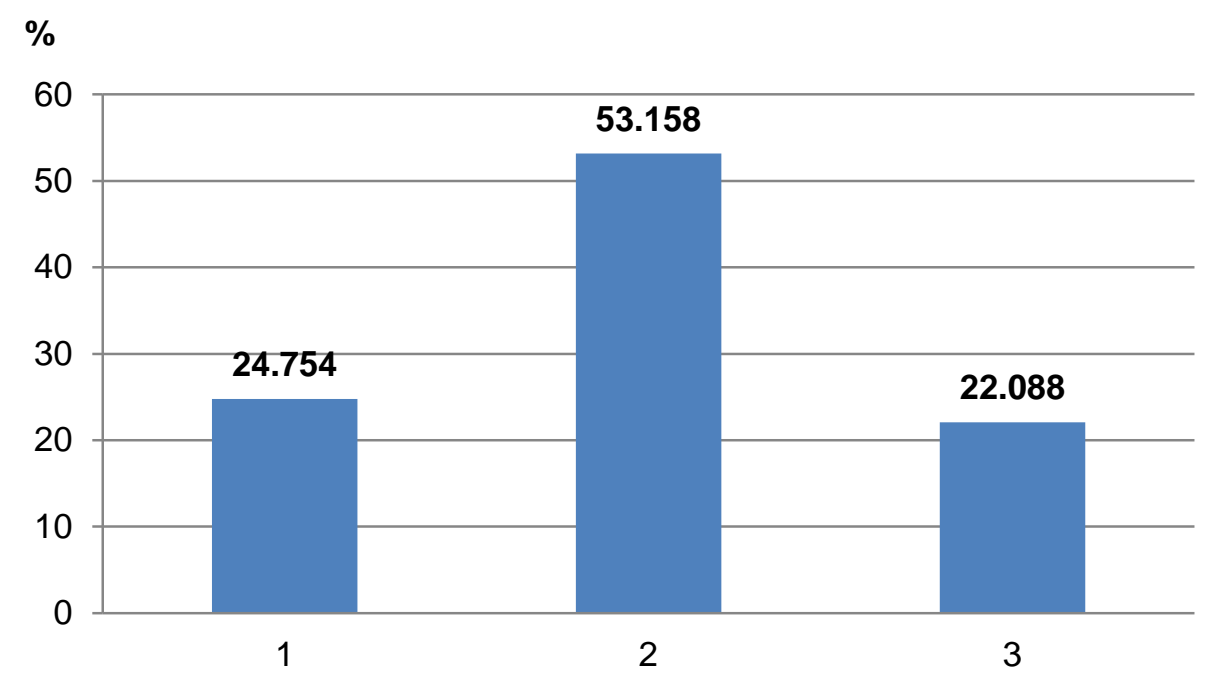

Figure 2. Percentage distribution of working time of combine in wheat harvesting:

1 - time for prepare and finish work, 2 - productive time; 3 - non-productive time in the field

Figure 2 shows the percentage distribution of the working time of the combine harvester. It can be seen that the preparatory and finish time is almost equal to the non-productive time of the field. Good organization of work and high staff qualification would reduce these times, which in turn will lead to a higher share of productive time, and the combine harvester performance will increase.

On the basis of the conducted study, an algorithm for working the combine harvester during the working day was made when unloading the grain hopper is carried out in stopped position (Figure 3).

The working day starts with maintenance, after which the combine harvester moves to the field, couples the header and the harvester moves into the field where it will work.

After beginning of harvest, there are several options:

- in case of malfunction the combine stops for repair;

- at the end of the field (at headland) the combine makes a turn;

- when loading the hopper the combine stops for unloading.

These three cases form the non-productive time of combine harvester in the field. After troubleshooting, turning or unloading grain the combine continues harvesting. When the working day is over and the field is not harvested, a transport is carried out to the end of the field, the header is uncoupled and the combine harvester is transported to the farm.

IRTIIE Vol. 7, No. 4, 2019 ISSN 1314-8788 (print), ISSN 1314-8796 (online), doi: 10.15547/artte.2019.04.001 


\section{IRTTIE}

Ipplied Researroches in Technics, Technologies and Eduration Journal of the Faculty of Technics and Technologies, Trakia University https://sites.google.com/a/trakia-uni.bg/artte/

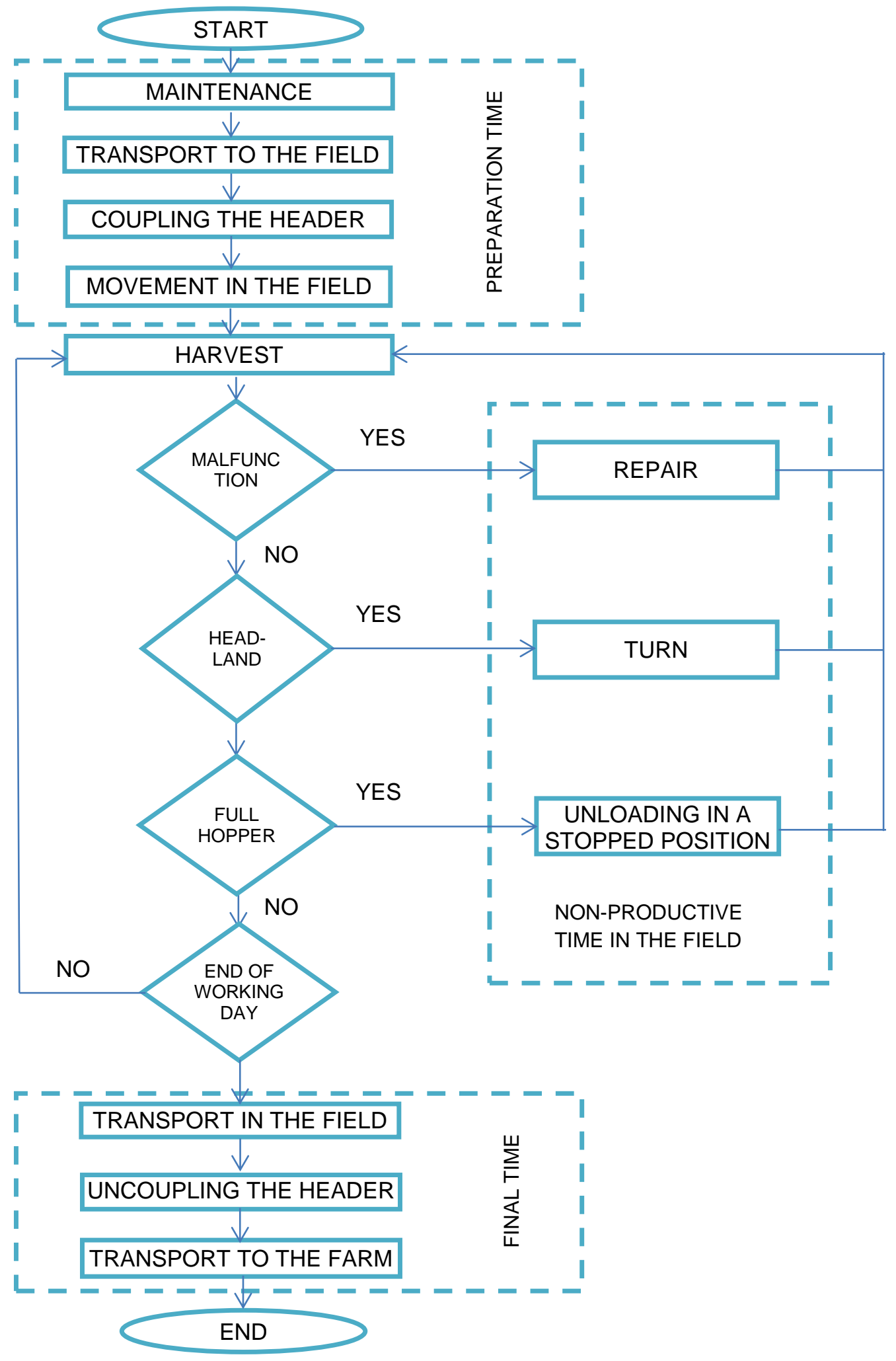

Figure 3.

A algorithm of work of combine harvester when unloading of grain hopper in stopped position

IRTIIE Vol. 7, No. 4, 2019 ISSN 1314-8788 (print), ISSN 1314-8796 (online), doi: 10.15547/artte.2019.04.001 


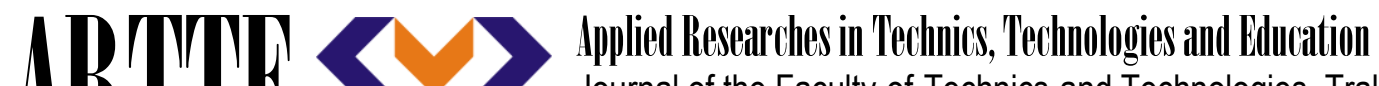 Journal of the Faculty of Technics and Technologies, Trakia University https://sites.google.com/a/trakia-uni.bg/artte/}

\section{CONCLUSIONS}

From the study of the work of the combine harvester throughout the harvesting campaign, it was found that the productive time of the combine harvester was $53.158 \%$ of the total working time. For preparatory and final operations, $24.754 \%$ of the time is spent. The nonproductive time in the field is $22.088 \%$ of the total working time. The unloading of grain hopper takes $14.842 \%$ of the total working time. It is recommended in adjacent smaller fields to work with fewer combine harvesters in the group, which will reduce the time lost for moving the combines between the fields.

\section{REFERENCES}

[1] Delchev N., Trendafilov K., Tihanov G., \& Stoyanov Y. (2016). Grain Combines Productivity According to Various Unloading - in the Field and at the Edge of the Field, Agricultural science and technology, 8 (3): 221-226.

[2] Tihanov G. (2017). Study on the Process of Unloading Grain Harvesters at the End of the Field, Agricultural science and technology, 9 (2): 129-131.

[3] Tihanov G. (2018). Study on the Duration of Operations Performed by Transport Vehicles During Unloading of the Grain Harvester Hopper, Applied Researches in Technics, Technologies and Education, Journal of the Faculty of Technics and Technologies, Trakia University, 6 (3): 232-236.

[4] Tihanov G., Petkova G. \& Tsatsarov M. (2018). Study of the Method of Grain Harvester Hopper Unloading and Full Hopper Signaling Used, Applied Researches in Technics, Technologies and Education, Journal of the Faculty of Technics and Technologies, Trakia University, 6 (2): 90-96.

[5] Trendafilov K., Delchev N., Kolev B. \& Tihanov G. (2017). Study on the Emptying Time of Grain Harvester Hoppers, Agricultural science and technology, 9 (4): 291-295. 